\title{
Investigating Geometrical Size Effect on the Flexural Strength of the Ultra High Performance Fibre Reinforced Concrete using the Cohesive Crack Model
}

\author{
Awinda,Kenneth*, Chen, Jiye and Barnett, Stephanie J \\ School of Civil Engineering \& Surveying, University of Portsmouth, UK \\ Corresponding address: kenneth.awinda@port.ac.uk
}

Key words: ultra high performance fibre reinforced concrete, geometrical size effect, cohesive crack model, cohesive elements, crack propagation.

\begin{abstract}
Geometrical Size Effect on the Flexural Strength of the Ultra High Performance Fibre Reinforced Concrete was investigated by experimental test data and numerical simulation. Comparison of the simulation results to existing experimental test results indicates that the Cohesive Crack Model (CCM) with a bilinear traction-separation curve can provide predictions of both the load-deflection curves and peak load of 100 and $150 \mathrm{~mm}$ deep UHPFRC test specimens to $=/-6 \%$ with a little size effect observed on the flexural strength. However, for the $50 \mathrm{~mm}$ deep beams a difference of $=1-25 \%$ was observed between model predictions of the peak load and experiment test data possibly due to a surface layer size effect.
\end{abstract}

\subsection{Introduction}

Concrete-based materials have many important applications within building and civil engineering construction. However their brittleness makes crack formation and growth critical to their mechanical behaviour and has in many cases limited the way in which they can be used.

Ultra high performance fibre reinforced concrete (UHPFRC) is a relatively new construction material with significantly higher compressive and tensile strength in addition to having much more ductility compared to normal reinforced concrete. The development of UHPFRC can be viewed within a historical context of continuing efforts to improve crack resistance of concrete based materials (Richard and Cheyrezy, 1994). Due to its enhanced fracture properties, UHPFRC has many potential applications both in the construction of new and rehabilitation of old structures.

However, a better understanding of its mechanical behaviour and its crack propagation properties is still required from both experimental study and numerical modelling (Habel (2004) and Lappa (2007)). As the cost of testing UHPFRC is considerably more compared to normal concrete numerical modelling and simulation has the potential to significantly reduce the number of experiment tests required for UHPFRC. 
Elices and Planas (1988) proposed a framework for classifying concrete models based on the damage mechanisms occurring within and outside the fracture zone and the adopted crack localisation criteria. Though damage within the fracture zone will always result in energy dissipation from the surrounding material, the linear elastic assumption within the material bulk is adopted in many commonly used concrete models where the effect on the overall result is observed to be small. Models incorporating this assumption have been used successfully with both discrete crack (Hillerborg et al., 1976) and crack band (Bažant and Oh, 1983) localisation approaches to model the load-deflection curves and failure loads for UHPFRC. For example the smeared concrete model in ABAQUS used by Le (2008) to model UHPFRC load-deflection curves uses the crack band localisation approach. The model also assumes that damage involves only stiffness degradation so that unloading occurs to the origin. The Concrete Damage Plasticity (CDP) model in ABAQUS used by Mahmud et al. (2013) on the other hand to model UHPFRC specimens adopts general damage within both the material bulk and fracture zone involving both stress loss and stiffness degradation. Though CDP adopts a crack band (smeared crack) localisation approach, it can be classified as a 'damage model' in that its constitutive formulation uses the internal variables which are more sophisticated in representing real life materials.

However, analytical studies by Habel (2004) and Lappa (2007) and numerical work by Le (2008) on modelling UHPFRC cite the difficulty in determining the appropriate reference length as being a significant limitation in applying the smeared crack approach to UHPFRC with a suggestion that the use of cohesive crack models (CCM) may be more appropriate for eliminating this difficulty. Su (2010) has also suggested that the discrete crack approaches in general and the cohesive crack models in particular could be more appropriate in cases where macro-cracks with strong discontinuity need to be modelled and which lend themselves to the use of cohesive interface elements in finite element methods.

Compared to other factors that could influence its mechanical behaviour such as fibre type, content and distribution, studies to fully establish the size effects of UHPFRC specimens are limited (Mahmud et al., 2013), most likely due to the high cost involved in testing the wide range of sizes required.

Size effect refers to the variation of the specimen strength with specimen size and generally in concrete nominal strength is observed to decrease with increase in specimen depth. However, of the limited studies of size effect reported for UHPFRC, there are significant inconsistencies some finding a significant size effect ((Le, 2008)) and others little (Spasojevic et al. (2008);Wille and Parra-Montesinos (2012)).

A recent study on size effects by Mahmud et al. (2013) concluded that there is little size effect on the beam nominal strength of UHPFRC specimens due to the material's high ductility. However the specimens used were geometrically similar only in their notch/depth ratio but not in their overall span/depth ratio. 
Some of the main sources of size effects in concrete-based material relate to the boundary layer effect and fracture mechanics (Bažant and Planas, 1998). However, for concrete-based materials the size effect caused by fracture mechanics is thought to be the most significant (Bažant and Planas, 1998). The fracture mechanics size effect is caused by the fact that larger structures release more strain energy per unit crack extension compared to smaller ones. Hence crack propagation and failure in larger structures would be expected to occur at lower nominal stresses. Brittle materials exhibit a stronger size effect because they have no mechanism to restrict crack growth with resulting strain energy released being used to further propagate cracks. Ductile materials on the other hand have different ways of inhibiting crack propagation and hence have higher fracture energy.

Concrete size effect response lies between that of purely ductile materials which exhibit no size effect and that of pure brittle materials that have a strong and constant size effect (Bažant and Planas, 1998).

This study benefits from access to test data from previous experiments carried out on geometrically similar UHPFRC specimens. As the crack path is known in advance, the cohesive crack model will be used with interface elements to simulate progressive crack propagation and failure mechanism of UHPFRC test specimens, and predict their load capacities. The modelling results will be compared to existing experimental test results with a view to investigating the influence of specimen size.

\section{$2.0 \mathrm{CCM}$ formulation}

The cohesive crack model (CCM) assumes that the stress-strain behaviour for concrete is isotropic linear elastic before cracking starts (Hillerborg et al., 1976) after which the fracture (cohesive) zone is replaced by a single crack that can still transfer the remaining cohesive stress. Cracks are initiated at a given point using criteria such as the maximum principal stress at that point reaching the tensile strength. The orientation of the crack at that point is perpendicular to the principal stress direction. The crack evolution is such that the cohesive stress $(\sigma)$ is a function of the crack opening (w). For concrete, this function decreases with crack opening width (w) and is therefore called the softening curve. The function defining the curve can be written as:

$$
\sigma=f(w)
$$

The area below the $\sigma$-w curve is equal to the fracture energy $G_{f}$ such that.

$$
G_{f}=\int \sigma d w
$$

If the general shape of the $\sigma$-w curve for concrete based material is known, a good estimate of the curve for a specific mix can be made from a determination of fracture 
energy and tensile strength (Hillerborg, 1980). However, one of the limitations of the Cohesive Crack Model is the difficulty in obtaining the parameters required as material inputs. While the difficulties of performing stable direct tensile test for concrete are well documented (Petersson, 1981), fracture energy values obtained by the commonly used three point test on notched specimens have been observed to be size dependent (Abdalla and Karihaloo, 2003).

Unlike normal concrete where a bilinear softening curve is generally accepted as providing good results, there is still a lack of agreement as to which curve is best for UHPFRC. The ideal way to obtain the complete softening curve is via a stable direct tensile test which in practice has been found to be extremely difficult. Inverse analysis from bending tests like Three Point Bending (TPB) has been adopted by several studies but differences still exist with suggestions including bilinear (Yoo et al., 2013) , trilinear (Kang et al., 2010) and exponential (Denneman et al., 2011) softening relations.

While CCM is very well suited to analysing failure by single or discrete cracks perpendicular to applied tensile loading, many materials have multiple cracks which are randomly distributed and oriented. The use of CCM is justified in this study where specimens are used in which the location of the predominant crack is known in advance to be in the notched section.

\subsection{Constitutive response of cohesive elements}

Cohesive elements can simulate several types of behaviours at interfaces where the interface load carrying capability is lost (Chen, 2009). The cohesive elements in ABAQUS FE software have been adopted in this study as they are based on the cohesive crack model by Hillerborg et al. (1976).

The cohesive elements used in this study are formulated using a stress-crack width curve that is typically characterized by peak strength $(\sigma)$ and fracture energy $\left(\mathrm{G}_{\mathrm{f}}\right)$ (fig 1) (Simulia, 2013)

Fig. 1: Simplified traction-separation curve

These cohesive elements are based on an initial linearly elastic response followed by damage as described below.

\subsubsection{Pre-Damage response}

Linear elasticity defines behaviour before initiation of damage with nominal stress and strain quantities used by ABAQUS for the traction separation law. Hence a unit 
thickness is specified for the element so that the nominal strain corresponds to the separation value. The elastic modulus for traction separation law is interpreted as a penalty stiffness $K_{n}$ such that for the normal direction

$$
K n=\frac{\sigma_{n(\max )}}{w_{\text {init }}}
$$

Where $\sigma_{n(\max )}$ is the maximum normal principal stress and $w_{\text {init }}$ is the initial separation or damage scale.

\subsubsection{Damage initiation}

ABAQUS provides four damage initiation criteria which can be based on either traction or separation.

The Quadratic nominal stress criterion was used and has the following formulation:

$\left[\frac{\left\langle\sigma_{n}\right\rangle}{\sigma_{n(\max )}}\right]^{2}+\left[\frac{\sigma_{s}}{\sigma_{s(\max )}}\right]^{2}+\left[\frac{\sigma_{t}}{\sigma_{t(\max )}}\right]^{2}=1$

Where the nominal and maximum principal stresses in the normal directions are $\sigma_{n}$ and $\sigma_{n(\max )}$ respectively and the corresponding stresses in the shear directions are $\sigma_{s}, \sigma_{t}, \sigma_{s(\max )}$ and $\sigma_{t(\max )}$

\subsubsection{Damage evolution}

Damage evolution describes the rate of degradation of material stiffness once initiation criteria is satisfied (Simulia, 2012). Formulation is based on a scalar damage approach whereby post damage-initiation stress $\left(\sigma_{1}\right)$ is related to stress without damage ( $\left.\sigma_{E}\right)$ as follows (fig.2):

$$
\sigma=(1-d) \sigma_{E}
$$

where $d$ is the scalar damage variable which incorporates the combined effect of all damage mechanisms. The $\mathrm{d}$ monotonically increases from 0 to 1 such that when:

$d=0$ : material is undamaged and

$d=1$ : material is fully damaged 
Initial stiffness,

$$
\mathrm{K}_{\mathrm{o}}=\sigma_{\mathrm{E}} / \mathrm{W}_{1}
$$

Substituting $\sigma_{\mathrm{E}}$ from (6) into (5) and re-arranging gives scalar damage variable as follows:

$$
d=1-K / K_{0}
$$

Where $K=\sigma_{1} / W_{1}$

Fig 2: Typical damaged response

Damage evolution is based on either energy or displacement requiring specification of either the total fracture energy or the post damage-initiation effective displacement at failure. It may depend on mode mix which may be defined either in terms of energy or traction

Energy-based damage evolution was used whereby the fracture energy can be defined as a function of mode mix using the Benzeggah-Kenane (BK) analytical form:

$$
G_{f}^{I}+\left(G_{f}^{I I}-G_{f}^{I}\right)\left(\frac{G_{f}^{S}}{G_{f}^{T}}\right)^{\eta}=G_{f}
$$

Where $G_{f}$ is the total mixed-mode fracture energy, $G_{f}^{I}$ is the normal strain energy release rate, $G_{f}^{I I}$ and $G_{f}^{I I I}$ are the shear strain energy release rates in two directions respectively and $G_{f}{ }^{s}=G_{f}^{I I}+G_{f}^{I I I}$. The total strain energy release rate $G_{f}{ }^{T}=G_{f}^{I}+G_{f}{ }^{s}$. The above BK law is suitable for the case when $G_{f}{ }^{I I}=G_{f}{ }^{I I I}$. Hence for isotropic failure the response is insensitive to the value of $\eta$ allowing the use of any valid value for it. 
The fracture energy was assumed to be equal for all the three modes so that $G_{f}=G_{f}^{I}=G_{f}{ }^{I I}=G_{f}{ }^{I I I}$. Benzeggah-Kenane (BK) analytical was selected as the mixed-mode behaviour with $\eta=2.284$.

\subsection{Material and methods}

\subsection{Material properties, Geometry and loading}

UHPFRC is still a relatively new material compared to normal concrete and only interim guidance currently exists for testing of UHPFRC in contrast to FRC which has standard test by RILEM and ASTM. Hence material data for it reported in literature are still limited. In this study, values of Young's Modulus (E) and tensile strength $\left(\sigma_{t}\right)$ are estimated from available data.

The specimens had $2 \%$ fibre content by volume consisting of straight high tensile steel fibres $13 \mathrm{~mm}$ long and $0.2 \mathrm{~mm}$ in diameter. Table 1 shows the mix proportion.

Table 1:UHPFRC Mixture Proportions

Load-deflection curves (fig.3) from deformation controlled Four Point Bend (FPB) tests (fig.4) on unnotched 100X100X350 mm UHPFRC specimens have been used to estimate both the Young's modulus and tensile strength of the mix following guidance in AFGC interim recommendations (AFGC, 2002).

Fig 3: Load-deflection curve for $2 \%$ fibre content

Fig 4: Four Point Bend (FPB) Test Arrangement

\section{Young's modulus (E)}

The slope $(P / \delta)$ of the initial linear range of the load-deflection curve (fig.3) is used in the linear elasticity based formula to estimate $E$ as follows: 


$$
E=\frac{P}{\delta} \times \frac{L^{3}}{48 I}
$$

where Moment of Inertia $I=\frac{b d^{3}}{12}$ with cross-sectional depth, $\mathrm{d}$ and breadth, $\mathrm{b}$ and span of the test specimen $=\mathrm{L}$.

A value of $44654 \mathrm{MPa}$ was obtained. Ductal, a proprietary UHPFRC mix similar to that adopted in this study is reported to have $E$ values of $47,000 \mathrm{MPa}$ (VSL, 2008).

\section{Tensile strength}

No tensile test data was available for the UHPFRC mix being studied. An estimate of the flexural tensile strength $\left(\sigma_{f}\right)$ was made using the load at the end of the linear elastic range (fig.3) as follows:

$$
\sigma_{f}=\frac{P L}{b d^{2}}
$$

The tensile strength $\left(\sigma_{t}\right)$ is then obtained by adjusting the above values using the following scale effect expression (AFGC,2002):

$$
\sigma_{t}=\sigma_{f} \times \frac{2 \times\left(\frac{d}{d_{0}}\right)^{0.7}}{1+2 \times\left(\frac{d}{d_{0}}\right)^{0.7}}
$$

Where $d_{0}=100 \mathrm{~mm}$

A tensile strength $\left(\sigma_{t}\right)$ value of $8.56 \mathrm{MPa}$ was obtained compared to $8 \mathrm{MPa}$ reported for a propriety UHPFRC mix Ductal (VSL, 2008).

\section{Fracture Energy}

Fracture energy $\left(G_{f}\right)$ was estimated from Three Point Bend 100x100x350 mm specimen with $33 \mathrm{~mm}$ notch on the tension face. The fracture energy $\mathrm{G}_{\mathrm{f}}$ was calculated as the area under the load-deflection curves as follows (Abdalla \& Karihaloo (2003)):

$$
G_{f=\frac{1}{(W-a) B}} \int P d \delta
$$


Where $W=$ specimen depth, $a=$ notch length, $B=$ Specimen thickness, $P=$ applied load, and $\delta=$ displacement of the load point.

However, the softening part of the load-deflection Three Point Bend test curves for UHPFRC had long tails. Therefore, the average test curves were extrapolated to obtain an estimate of the area under the full load deflection curve. As per the equation above, the area was then divided by the effective crack area to obtain the

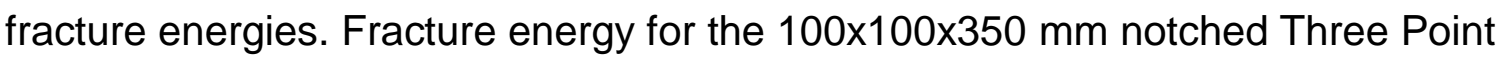
Bend specimen was estimated as $16.9 \mathrm{KJ} / \mathrm{m}^{2}$. Richard and Cheyrezy (1994) reported $\mathrm{G}_{f}$ values for UHPFRC of $10-40 \mathrm{KJ} / \mathrm{m}^{2}$ while Le (2008) found values between $19-38 \mathrm{KJ} / \mathrm{m}^{2}$.

Unlike for normal concrete where a bilinear softening curve is generally accepted for modelling, there is no general agreement on the most appropriate shape for UHPFRC stress-crack width relation. In the absence of direct tensile test data, some studies have adopted an inverse analysis to estimate post-peak behaviour. However, in the present study, a linear softening curve was adopted.

\subsection{Crack Modelling}

As confirmed by experimental observation (fig 5), the centreline of the specimen directly above the specimen was the cracking path into which cohesive interface elements were inserted (fig.6). Cohesive elements (COH2D4) were assigned to the interface using shared nodes.

Fig 5: Cracked specimens from TPB test

Fig 6: Simulation of cracked specimen

The bulk of the beam model was meshed with first order incompatible mode elements (CPE4I). These elements work well in bending and are compatible with cohesive elements when using shared nodes (Simulia, 2012)

The critical crack length $a_{m}$ is calculated as about $2.6 \mathrm{~mm}$ using values from Table 2 and the linear fracture mechanics based formula (Benham, 1996):

$$
a_{m}=G_{f} E / \psi^{2} \sigma^{2}{ }_{t} \pi
$$

where $\psi$ is cracking shape parameter taken as 1.12 in this study (Benham, 1996). The critical crack length governs the length of each cohesive element so that the actual modelled crack length should be less than the critical value. Therefore the 
$0.33 \mathrm{~mm}$ used as element length along potential crack path in this model ensures that modelling of the crack can be captured below its critical length (Chen, 2009)

\section{Results}

\subsection{Model validation}

Modelling simulation was carried out using the values in table 2 as estimated above. In addition poisson ratio value of 0.2 was adopted

Table 2: Modelling parameters

For the cohesive elements linear elastic properties were defined using the traction type. The initial damage scale $w_{\text {init }}$ and hence stiffness was estimated in relation to the bilinear stress-separation response shown in fig 1 . Hence

$$
\begin{gathered}
W_{\text {init }}=\sigma_{n(\max )} / K_{n} \\
K_{n}=E / h_{\text {eff }}
\end{gathered}
$$

Assuming effective thickness of cohesive elements $h_{\text {eff }}=1$ gives

$$
\mathrm{K}_{\mathrm{n}}=\mathrm{E}
$$

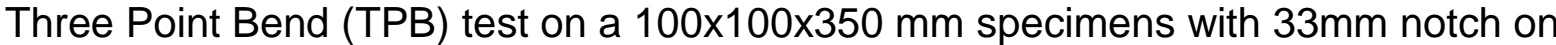
the tension face was simulated (fig.7 and 8 ) and the corresponding test results used for validation (fig.9).

Fig.7: TPB test arrangement

Fig.8: Test geometry

The cohesive crack model with a bi-linear $\sigma$-w curve produced a load-deflection curve whose shape closely matched those from test results in the elastic, hardening and softening phases.

Fig.9: Load deflection curves for $100 \times 100 \times 350$ specimen 
Micro-structural theory explains each of the phases in terms of the gradual engagement of the fibres to bridge micro-cracks after the linear elastic stage. From this point to the peak load, the energy provided by the externally applied load is not enough to overcome the fibre bridging action resulting in the formation of more micro-cracks in the strain hardening phase. However, beyond peak load, the fibres de-bond from the matrix leading to the softening phase and finally to failure through complete pull-out.

While CCM assumes a homogeneous and isotropic material at the macro-level, the scatter of the test results indicates the inherent heterogeneity of the material at the micro-level. The model also ignores the spread of cracks in the specimens and only simulates the dominant crack path. Attempts have been made by others (Yang et al, 2009) to simulate the complex crack patterns in concrete by pre-inserting cohesive elements within very fine and elaborate meshes. However, the approach adopted here is justified by the dominant crack path being known in advance and it accurately predicts the average curve with computational efficiency.

\subsection{Sensitivity study}

The values of tensile strength $\left(\sigma_{t}=8.5 \mathrm{MPa}\right)$ and fracture energy $\left(G_{f}=16.9 \mathrm{KJ} / \mathrm{m}^{2}\right)$ used in the model were estimated as described in 3.1. The sensitivity of the Loaddeflection curve predicted by the model to variation in the tensile strength $\left(\sigma_{t}\right)$ and fracture energy $\left(\mathrm{G}_{\mathrm{f}}\right)$ is investigated using the $50 \times 100 \times 350 \mathrm{~mm}$ UHPFRC test specimen.

\subsubsection{Tensile strength $\left(\sigma_{t}\right)$}

The effect of varying the tensile strength between 6-16 MPa for a constant fracture energy $\left(G_{\mathrm{f}}=16.9 \mathrm{KJ} / \mathrm{m}^{2}\right)$ is presented in fig. 10 below.

Fig 10: Load-deflection curves for different tensile strengths

The response of peak load to variation in the input tensile strength is significant and almost linear with a tensile strength increase of only $1 \mathrm{MPa}$ causing a $7 \mathrm{KN}$ increase in peak load (fig.11).

Fig 11: Variation of peak load with tensile strength

An increase in the tensile strength also produces a steeper post-peak slope and the response is almost exponential (fig.12).

Fig 12: Variation of post-peak slope with tensile strength 


\subsubsection{Fracture Energy, $\mathrm{G}_{\mathrm{f}}$}

The effect of varying the fracture energy values between $9-40 \mathrm{KJ} / \mathrm{m} 2$ representing the range of values quoted in literature (3.1) is shown in fig. 13 below. The tensile strength is kept constant at $8.56 \mathrm{MPa}$.

Fig 13: Load-deflection curves for different fracture energies

Change in the peak load with variation of fracture energy is also exponential but less sensitive relative to that of tensile strength with a $10 \mathrm{KJ} / \mathrm{m} 2$ increase in input fracture energy producing only a $4 \mathrm{KN}$ increase in peak load (fig.14).

Fig 14: Effect of fracture energy $\left(G_{f}\right)$ on Peak Load

However an increase in the input fracture energy produces an exponential decrease in the post-peak slope (fig.15)

Fig 15: Variation of post-peak slope with fracture energy

The sensitivity study suggests that the Young's Modulus, tensile strength and fracture energy values estimated in $\mathbf{3 . 1}$ were appropriate for this UHPFRC material as they produced good model prediction relative to the test results.

\subsection{Size effect}

The model is now used to study the effect of size on the flexural strength of notched UHPFRC specimens (Table 3) subject to TPB test (fig.7)

Table 3: Geometry of Three Point Bend (TPB) test specimens

For each specimen size comparison of modelling predictions with the available experiment test results are presented in figs.16-18 below.

Fig 16: Load-deflection curves for $50 \times 150 \times 550$ specimen 
Fig 17: Load-deflection curves for $50 \times 100 \times 350$ specimen

Fig 18: Load-deflection curves for $50 \times 50 \times 200$

Using a tensile strength of $8.56 \mathrm{MPa}$ estimated from test data with a bilinear traction separation curve $(\sigma-w)$ curve, the model has made predictions to $=/-6 \%$ of the average peak load for the $100 \mathrm{~mm}$ deep and $150 \mathrm{~mm}$ deep specimens and to $=/-25 \%$ for the $50 \mathrm{~mm}$ deep specimen (Table 4 ).

Table 4: Peak Loads

All the UHPFRC specimens had a notch/depth and depth/span ratios of $1 / 3$ (Table 3 ) hence satisfying the geometrical symmetry necessary to consider size effects (Bažant and Kazemi, 1990).

Nominal stress at peak load $P$ for a beam of span $L$ and width $b$ is chosen to coincide with flexural strength calculated based on elastic beam bending for three point test as follows:

$$
\sigma_{\mathrm{n}}=3 \mathrm{PL} / 2 b \mathrm{~h}^{2}
$$

The flexural tensile strength is assumed to be determined by the notched section so that the effective depth $h$ is the overall depth less the notch length

Bažant and Oh (1983) proposed the following to describe the size effect in concrete:

$$
\sigma_{n}=\beta \sigma_{t}^{\prime}\left(1+d / d_{0}\right)^{-1 / 2}
$$

where $\sigma_{t}^{\prime}$ is the direct tensile strength and $d$ is the depth while $\beta$ and $d_{0}$ are constants that depend only on fracture properties of the material and on the geometry (shape) of the structure and are obtained by curve fitting.

Squaring both sides of equation 19 and re-arranging provides a convenient plot for evaluating the size effect law (fig.19). Values below are for specimens of constant width $(50 \mathrm{~mm})$ all modelled with tensile strength $\sigma_{\mathrm{t}}=8.56 \mathrm{MPa}$ and fracture energy $\mathrm{G}_{\mathrm{f}}=16.9 \mathrm{KJ} / \mathrm{m}^{2}$

Fig.19: Size effect 
Apart from the small specimen (depth $=50 \mathrm{~mm}$ ) modelling predictions match test data very well in showing that the size effect for UHPFRC specimens is small. In order to establish size effects conclusively, a wider range of sizes is required with a range of $1: 8$ in depth recommended by Bazant and Kazemi (1990).

Modelling predictions extended to cover specimen depths $25-200 \mathrm{~mm}$ in line with the size range recommended above were consistent in indicating a small size effect (fig.19). These results agree with those of Spasojevic et al. (2008), Wille and ParraMontesinos (2012) and most recently Mahmud et al. (2013).

Failure in concrete is caused when micro-cracks localise into macro-cracks leading to a significant strain energy release that is enough to cause more crack propagation. However in UHPFRC when micro-cracks start to grow, fibre bridging is activated across the crack opening significantly increasing its fracture energy and ductility. The strain energy released by the micro-cracks is not enough to overcome the bridging action by fibres and to pull them out from the matrix in order cause crack localisation. Instead more micro-cracks are formed so that strain hardening is observed after the onset of first cracking and prior to softening. This increased ductility is enough to significantly reduce the fracture mechanics size effect in UHPFRC as predicted by the model.

However, in smaller specimens $(\mathrm{d}=50 \mathrm{~mm})$, size effect from sources linked to specimen preparation such as the boundary layer effect become significant producing the observed deviation from both the model prediction and the general trend of larger specimens. Previous studies (Barnett et al., 2007) have suggested that smaller UHPFRC specimens are subject to a size effect due to the influence of their surface layer (also called skin or wall effect). This surface layer effect is caused by the modifying influence of the mould on the surface of a specimen. For a UHPFRC specimen for example, the random orientation of the fibres will be restricted within the plane of the surface (Barnett et al., 2007). Fibres on the moulded surface will be aligned parallel to it and will therefore have a higher probability of bridging cracks that form in the perpendicular direction. Hence the surface or skin layer will have a higher strength than the inside of the specimen. The smaller the specimens the stronger this effect would be expected to be as the surface layer would constitute a larger proportion of the total cross-section.

\section{Conclusions and future work}

The cohesive crack model implemented through ABAQUS FE software has successfully predicted load-deflection curves for notched UHPFRC TPB specimens subject to load. Bilinear stress-separation curves used with cohesive elements 
inserted in a crack path known in advance have been found to be able to simulate crack propagation and to predict failure load in the UHPFRC material considered.

As expected the modelling predictions of the peak loads are most sensitive to the tensile strength which for UHPFRC is mainly based on the force required to pull fibres bridging the localised crack out of their surrounding matrix. Increasing the tensile strength makes the slope of the post peak load deflection steeper while increasing the fracture energy produces a shallower slope.

The size effect of depth of UHPFRC specimens on predicted material tensile strength is small most likely due to the fibre-bridging action across micro-cracks leading to a significant increase in fracture energy and therefore ductility. However, for small specimens (depth $=50 \mathrm{~mm}$ or less) the size effect due to factors linked to specimen preparation such as the wall effect appear to be significant. This surface layer (or skin) is stronger due to alignment of fibres parallel to it and is proportionately more influential in specimens of smaller cross-sectional area. The specimens' depth related size effect in these small specimens needs further investigation in order to evaluate the influence of these factors relating to specimen preparation. Future work will consider the influence of fibre content and length scale on the model prediction of failure response and geometrical size effect on UHPFRC materials.

\section{References}

Abdalla, H.M., Karihaloo, B.L., 2003. Determination of size-independent specific fracture energy of concrete from three-point bend and wedge splitting tests. Mag. Concr. Res., 55(2): 133-141.

AFGC, 2002. Ultra-high performance fibre-reinforced concretes: interim recommendations, Association Française de Génie (AFGC), Paris, France.

Barnett, S.J., Millard, S.G., Soutsos, M.N., Schleyer, G.K., Tyas, A., 2007. Flexural Performance of UHPFRC PROTECT2007: Structures under Extreme Loading, Whistler, BC, Canada, pp. 99.

Bažant, Z.P., Kazemi, M.T., 1990. Determination of fracture energy, process zone length and brittleness number from sixe effect, with application to rock and concrete. International Journal of Fracture, 44(2): 111-131.

Bažant, Z.P., Oh, B.H., 1983. Crack band theory for fracture of concrete. Materials and Structures, 16: 23.

Bažant, Z.P., Planas, J., 1998. Fracture and size effect in concrete and other quasibrittle materials. CRC Press, London.

Benham, P.P., Crawford, R.J.,Armstrong,C.G., 1996. Mechanics of Engineering Materials. Addison Wesley Longman Limited, Essex, England.

Chen, J., Ravey, E.,Hallet, S.,Wisnom, M.,Grassi, M., 2009. Prediction of delamination in braided composite T-piece specimens. Composites Science and Technology, 69: 5.

Denneman, E., Wu, R., Kearsley, E.P., Viser, A.T., 2011. Discrete fracture in high performance fibre reinforced concrete materials. Engineering Fracture Mechanics, 78: 11.

Elices, M., Planas, J., 1988. Material Models, RILEM.

Habel, K., 2004. Structural behaviour of elements combining ultra-high performance fibre reinforced concretes (uhpfrc) and reinforced concrete, École polytechnique fédérale de lausanne, Lausanne, EPFL. 
Hillerborg, A., 1980. Analysis of fracture by means of the fictitious crack model, particularly for fibre reinforced concrete. International Journal of cement composites, 2: 8.

Hillerborg, A., Modeer, M., Petersson, P.E., 1976. Analysis of crack formation and crack growth in concrete by means of fracture mechanics and finite elements. Cem Concr Res, 6(6): 773-781.

Kang, S.T., Lee, Y., Park, Y.-D., Kim, J.-K., 2010. Tensile fracture properties of an Ultra High Performance Fiber Reinforced Concrete (UHPFRC) with steel fiber. Compos Struct, 92: 11.

Lappa, E.S., 2007. High Strength Fibre Reinforced Concrete Static and fatigue behaviour in bending, Technische Universiteit Delft.

Le, T.T., 2008. Ultra high performance fibre reinforced concrete paving flags, University of Liverpool. Mahmud, G.H., Yang, Z., Hassan, A.M.T., 2013. Experimental and numerical studies of size effects of Ultra High Performance Steel Fibre Reinforced Concrete (UHPFRC) beams. Construction and Building Materials, 48: 8.

Petersson, P.E., 1981. Crack growth and development of fracture zones in plain concrete and similar materials, Division of Building Materials, Lund Institute of Technology Lund, Sweden.

Richard, P., Cheyrezy, M., 1994. Reactive powder concretes with high ductility and 200-800 MPa compressive strength. In: Mehta, P.K. (Ed.), Concrete Technology Past, Present and Future. American Concrete Institute, Detroit, Michigan, pp. 507-518.

Simulia, 2012. Modeling fracture in ABAQUS - course notes. simulia.

Simulia, 2013. Abaqus Analysis User's Manual. Simulia.

Spasojevic, A., Redaelli, D., Ruiz, M.F., Muttoni, A., 2008. Influence of tensile properties of UHPFRC on size effect in bending. In: Fehling, E., Schmidt, M., Stürwald, S. (Eds.), Second International Symposium on Ultra High Performance Concrete. Structural Materials and Engineering Series. Kassel University Press, Kassel, Germany, pp. 303-310.

Su, X., Yang, Z., \& Liu, G., 2010. Finite Element Modelling of Complex 3D Static and Dynamic Crack Propagation By Embedding Cohesive Elements in Abaqus. Acta Mechanica Solida Sinica, 23(3(12).

VSL, P.P.L., 2008. Ductal Parameters. In: Ltd, V.P.P. (Ed.).

Wille, K., Parra-Montesinos, G., 2012. Effect of Beam Size, Casting Method, and Support Conditions on Flexural Behaviour of Ultra-High-Performance Fiber-Reinforced Concrete. ACI Materials Journal, 109(3): 10.

Yang, Z.J., Su, X. T., Chen, J. F., \& Liu, G. H, 2009. Monte Carlo simulations of complex cohesive fracture in random heterogeneous quasi-brittle materials. International Journal of Solids and Structures, 46.

Yoo, D.-Y., Lee, J.-H., Yoon, Y.-S., 2013. Effect of fiber content on mechanical and fracture properties

of ultra high performance fiber reinforced cementitious composites. Compos Struct, 106: 12. 


\section{FIGURES AND TABLES}

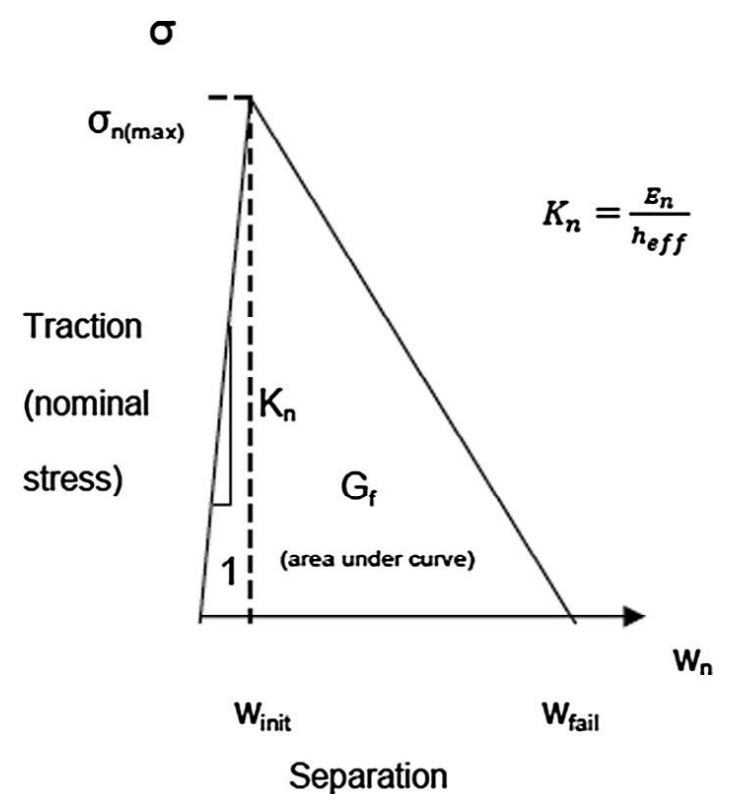

Fig. 1: Simplified traction-separation curve

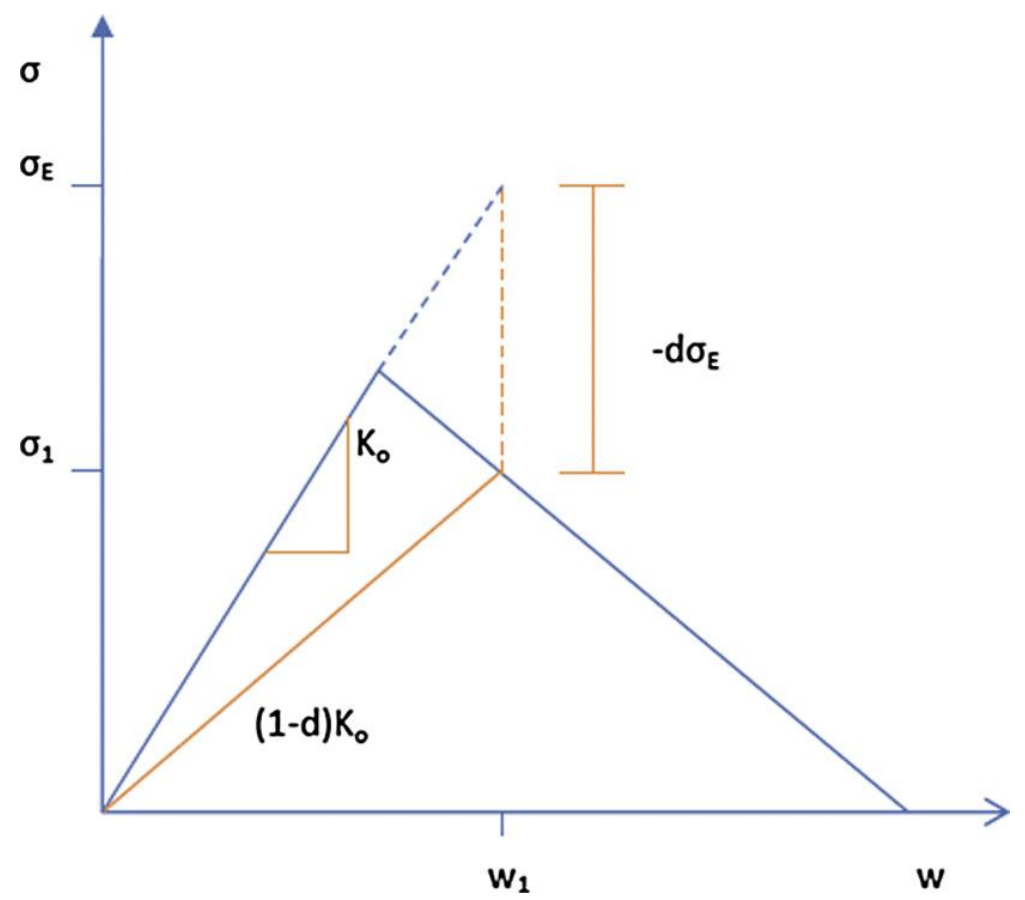

Fig 2: Typical damaged response 


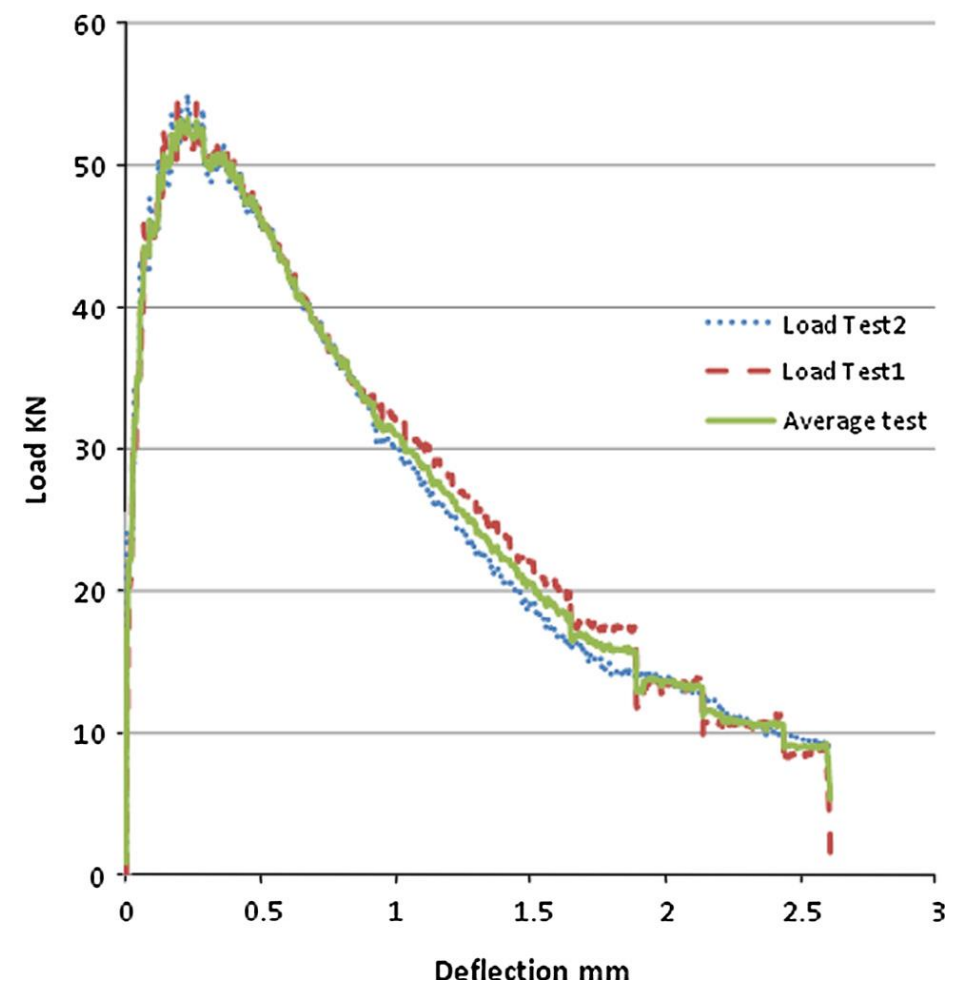

Fig 3: Load-deflection curve for $2 \%$ fibre content

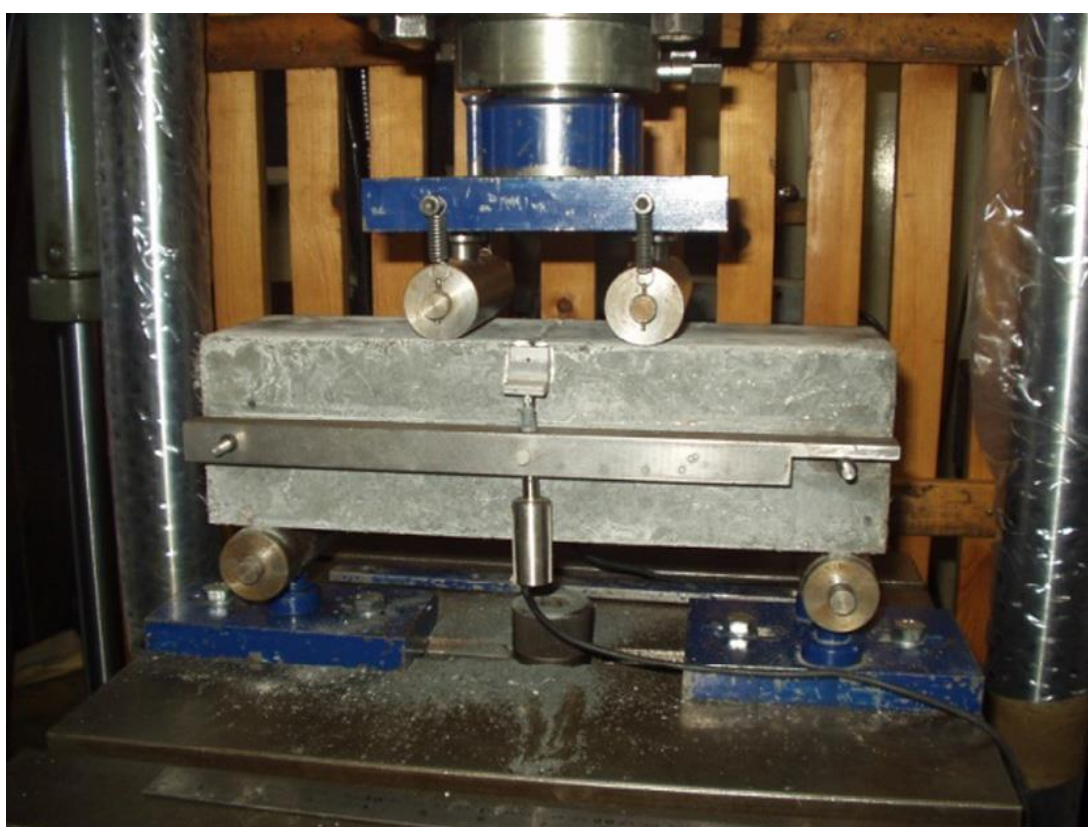

Fig 4: Four Point Bend (FPB) Test Arrangement 


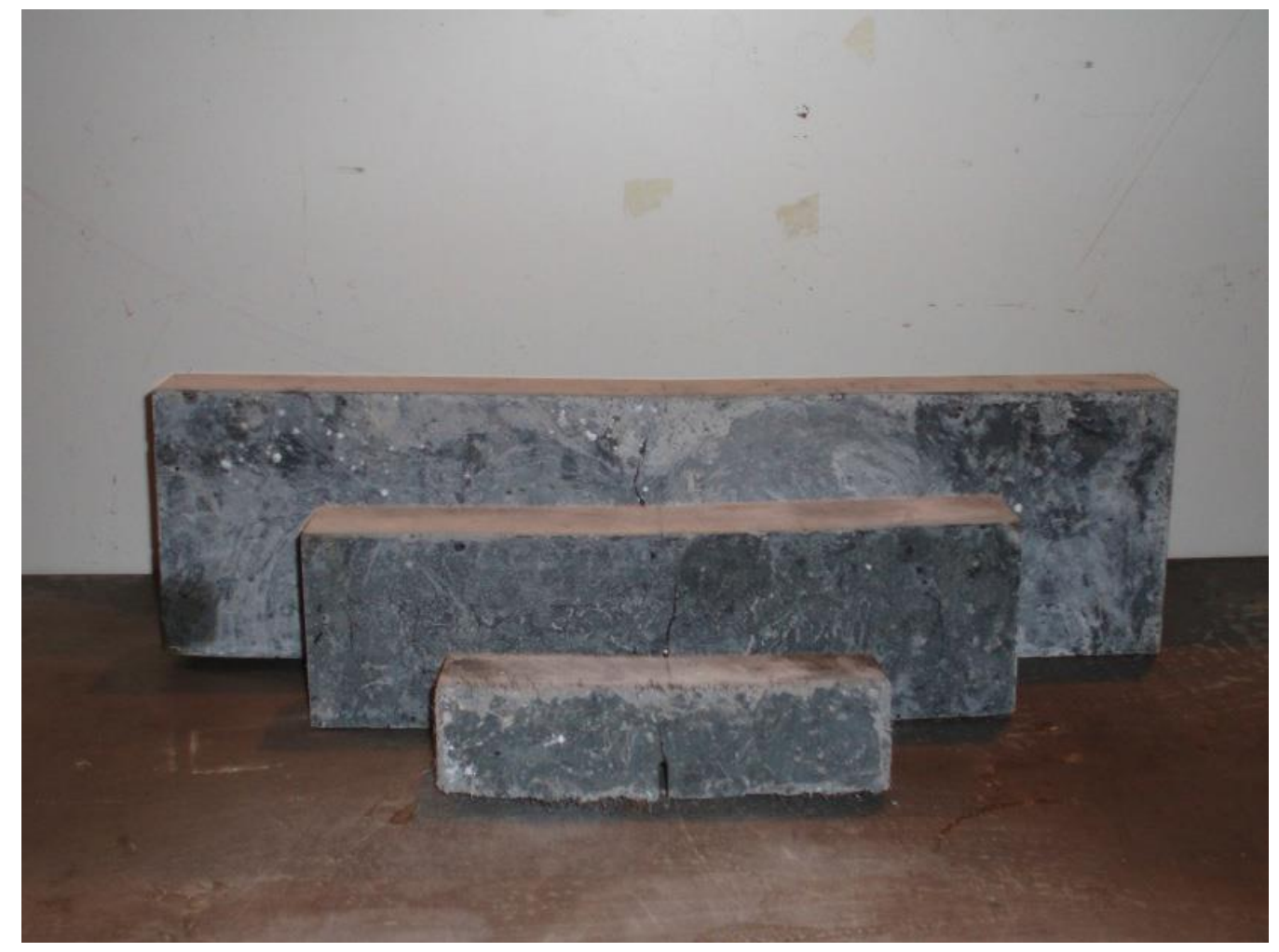

Fig 5: Cracked specimens from Three Point (TPB) test

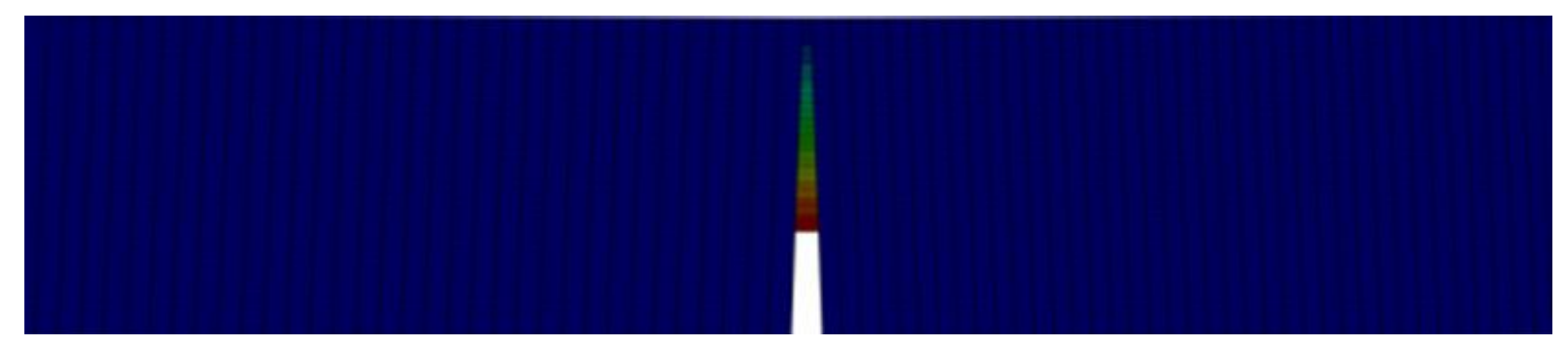

Fig 6: Simulation of cracked specimen 


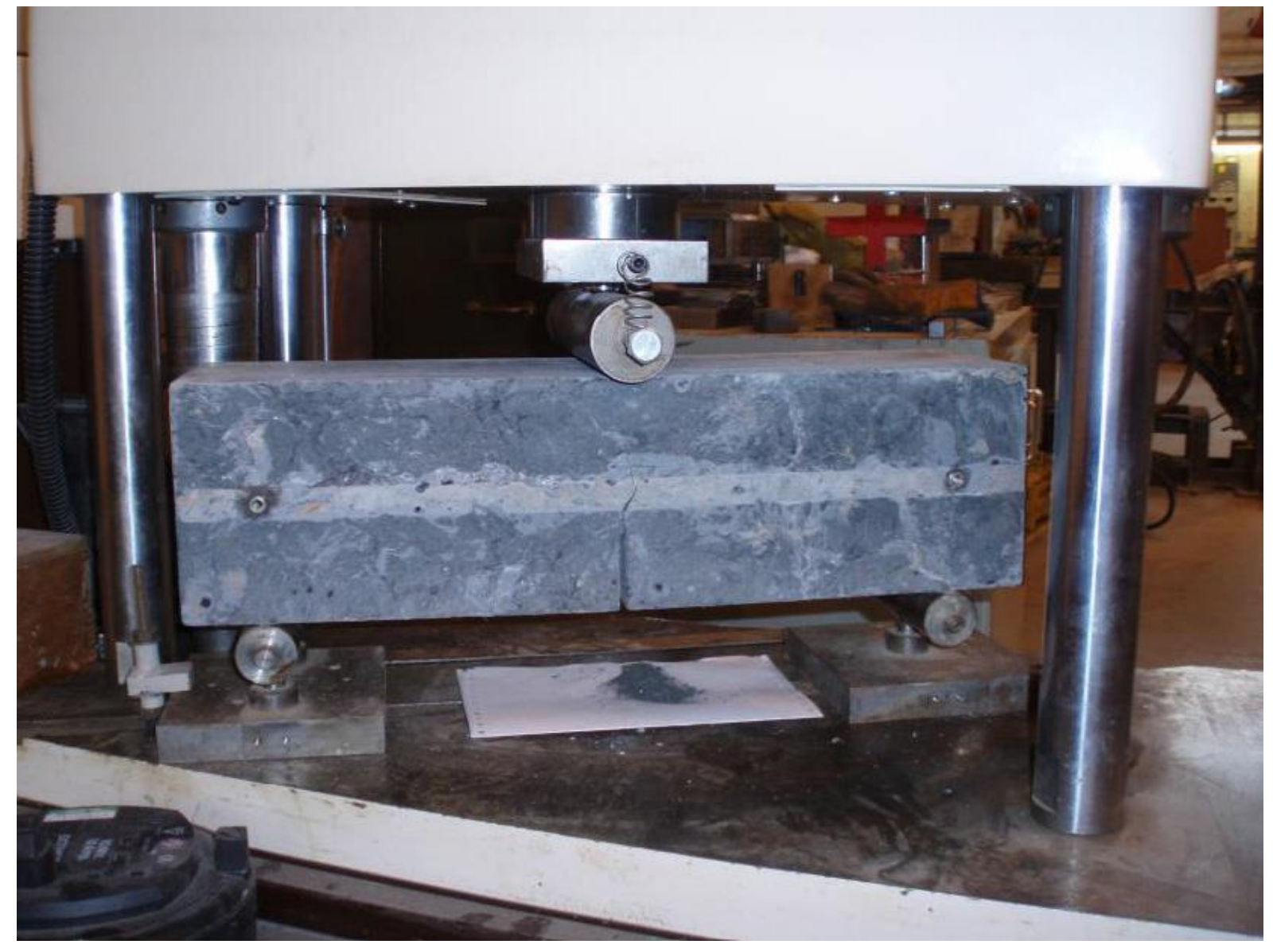

Fig.7: TPB test arrangement

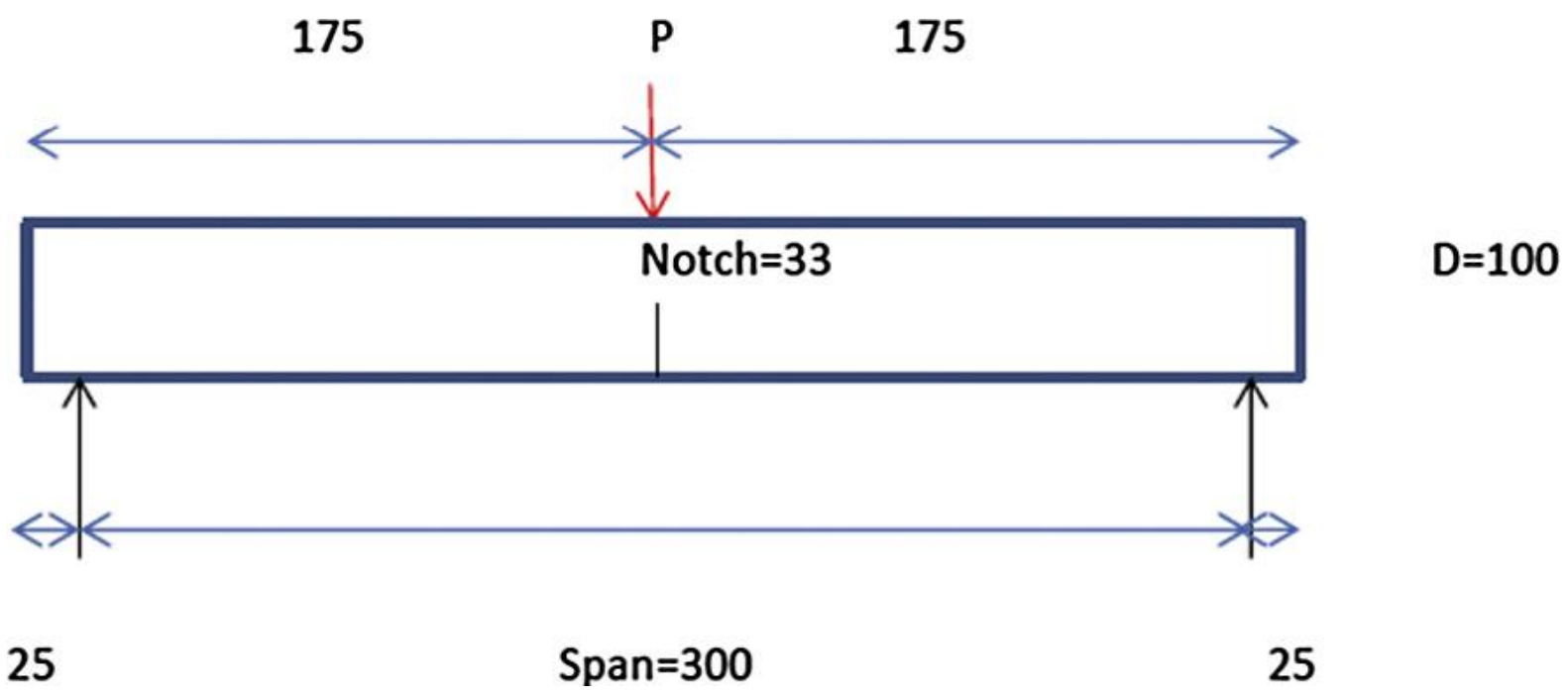

Fig.8: Test geometry 


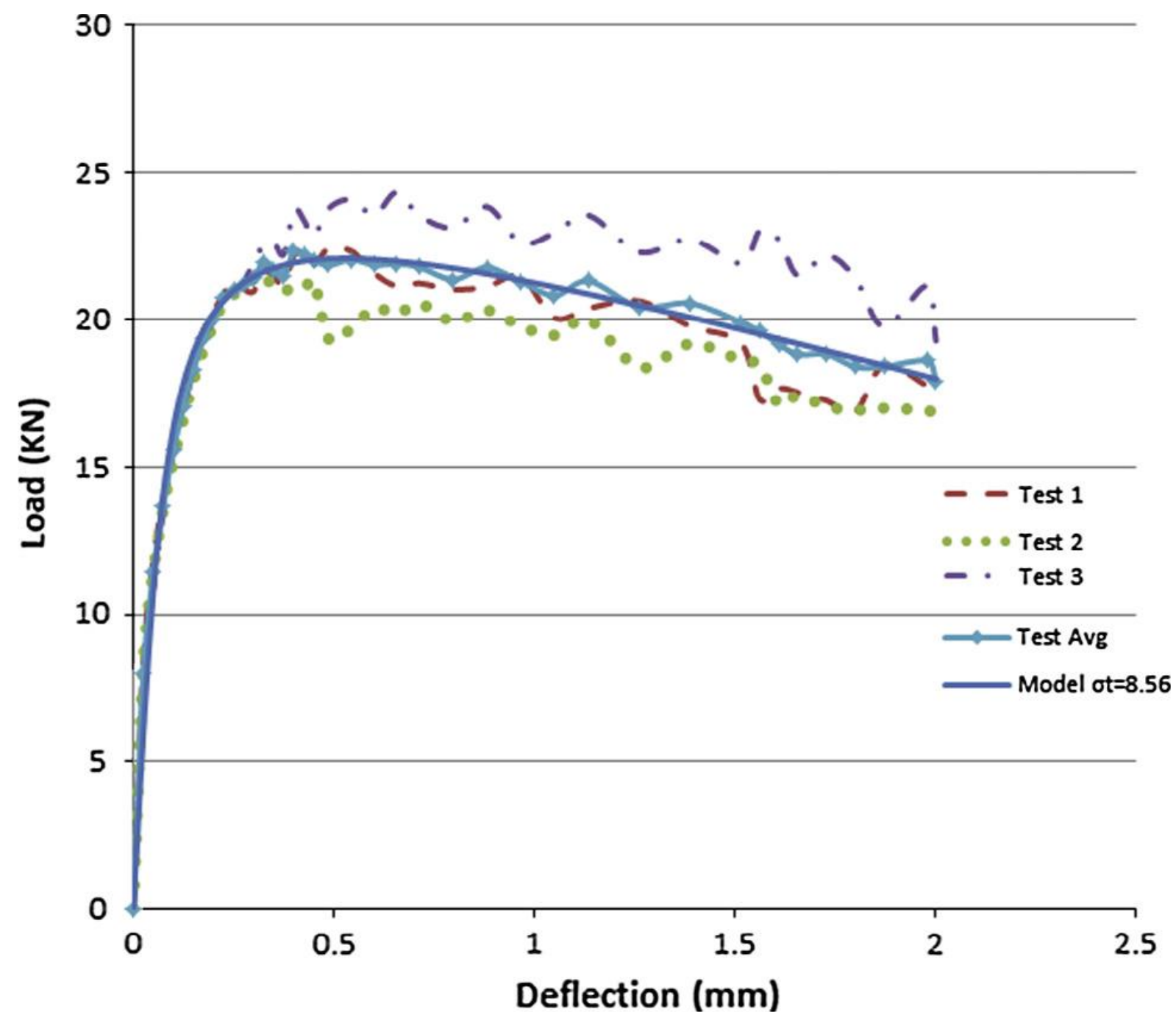

Fig.9: Load deflection curves for $100 \times 100 \times 350$ specimen 


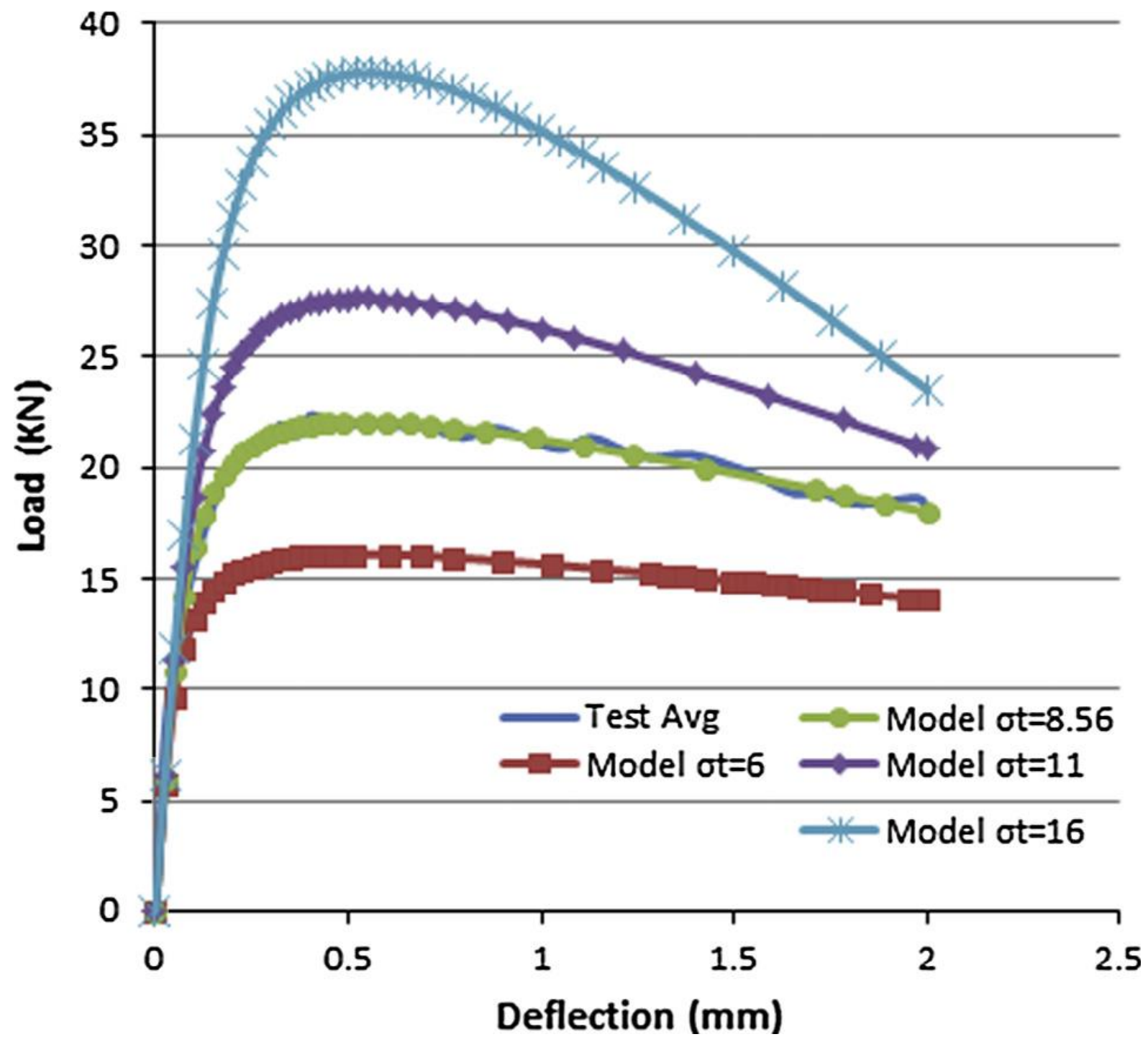

Fig 10: Load-deflection curves for different tensile strengths 


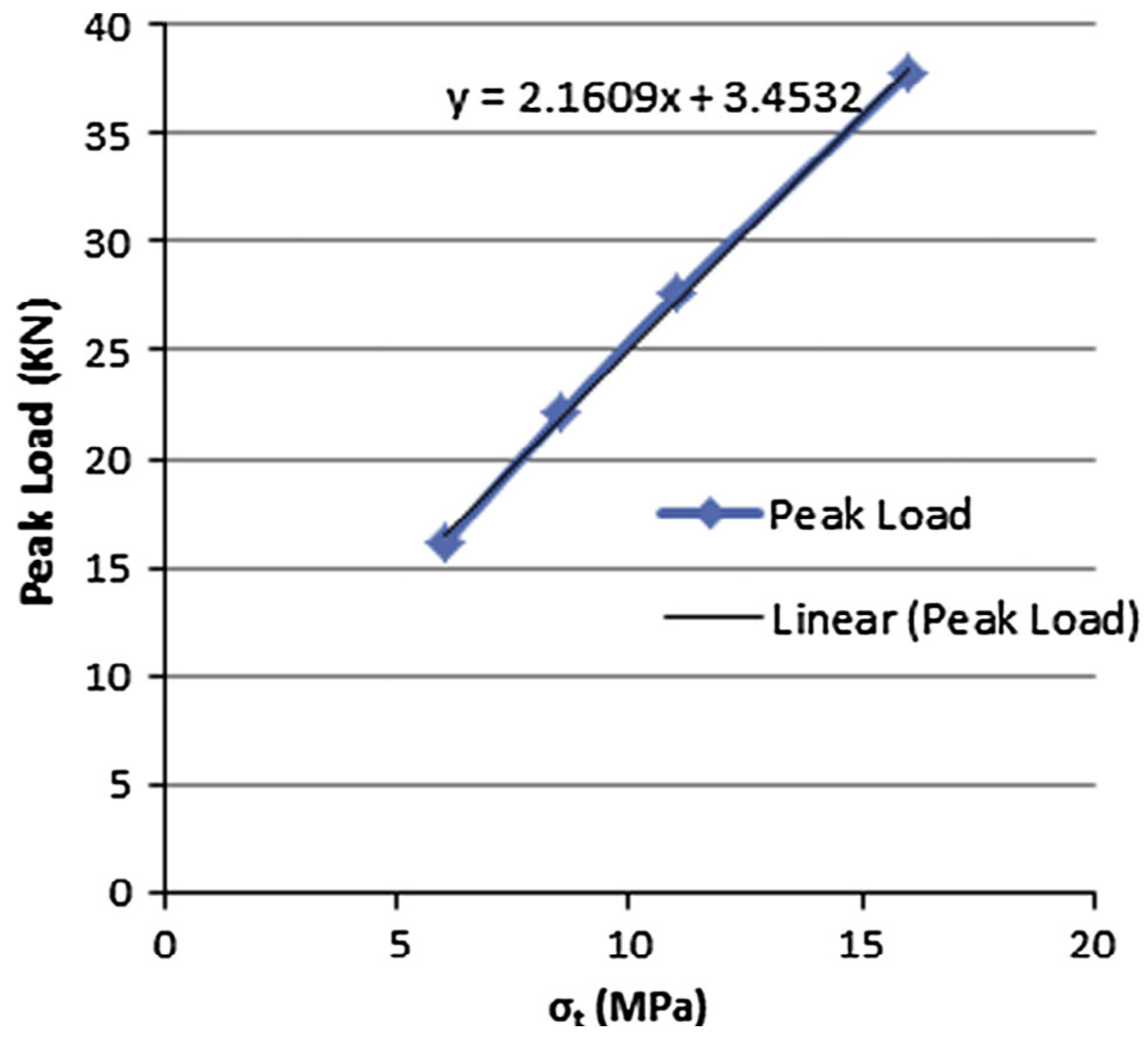

Fig 11: Variation of peak load with tensile strength 


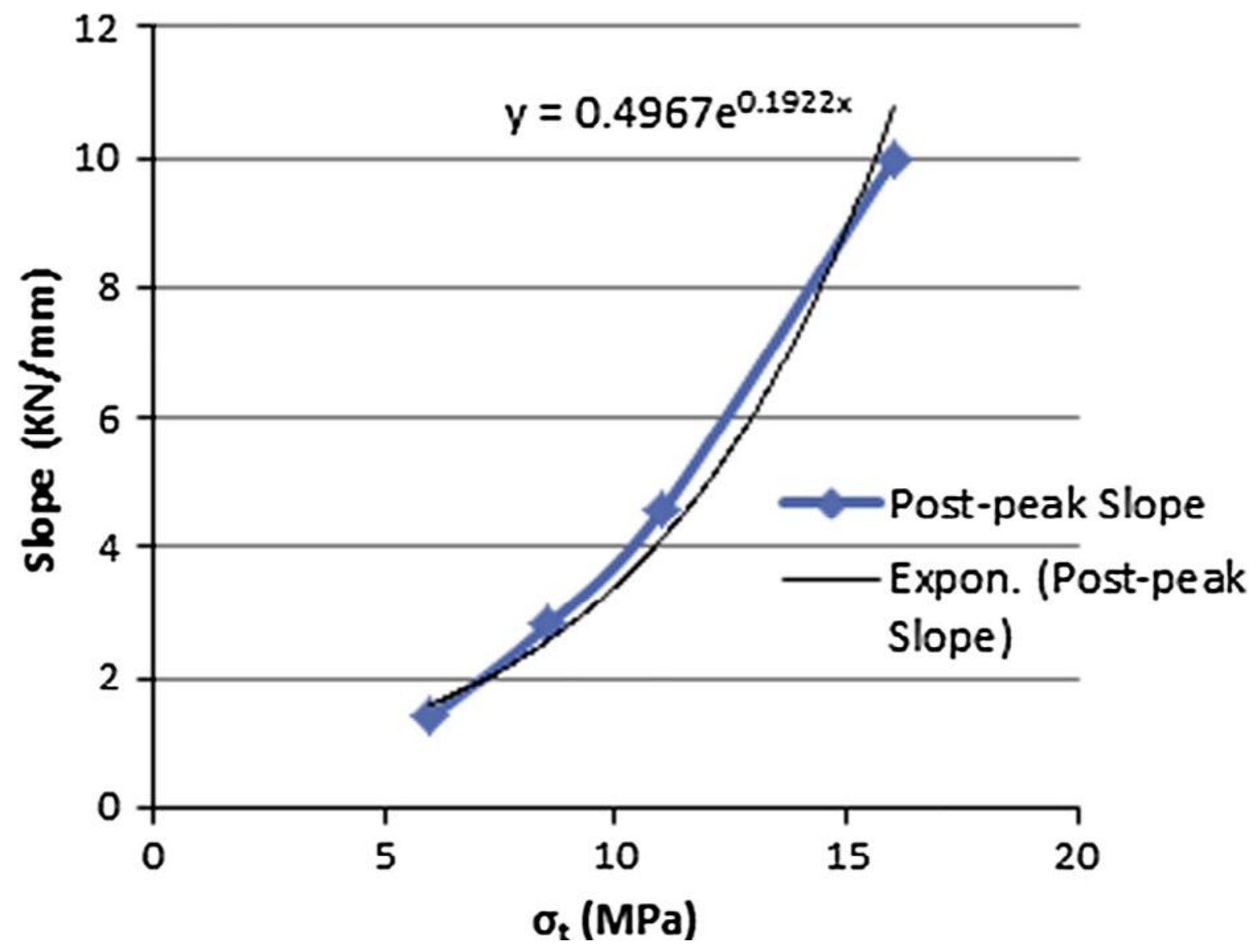

Fig 12: Variation of post-peak slope with tensile strength 


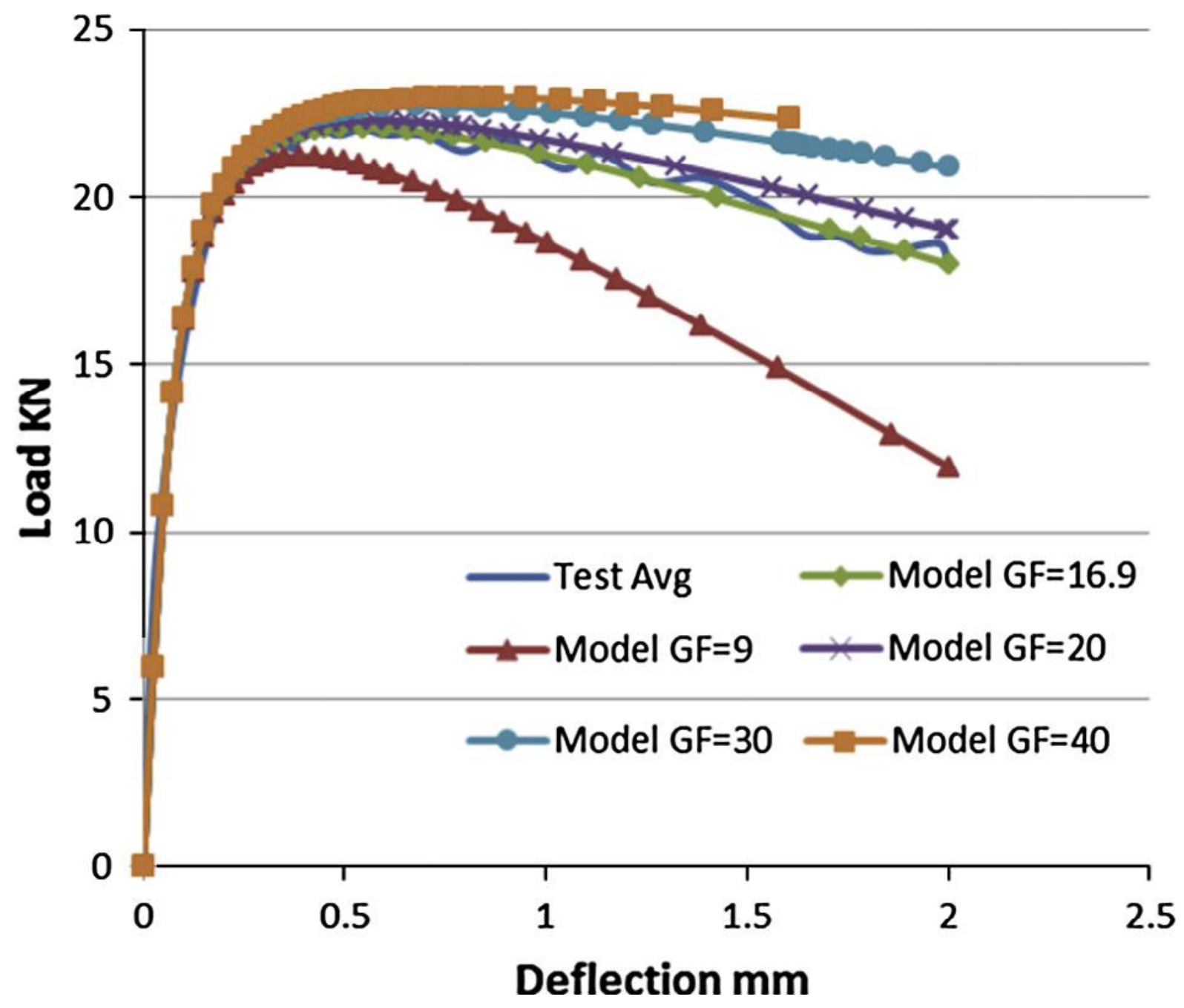

Fig 13: Load-deflection curves for different fracture energies 


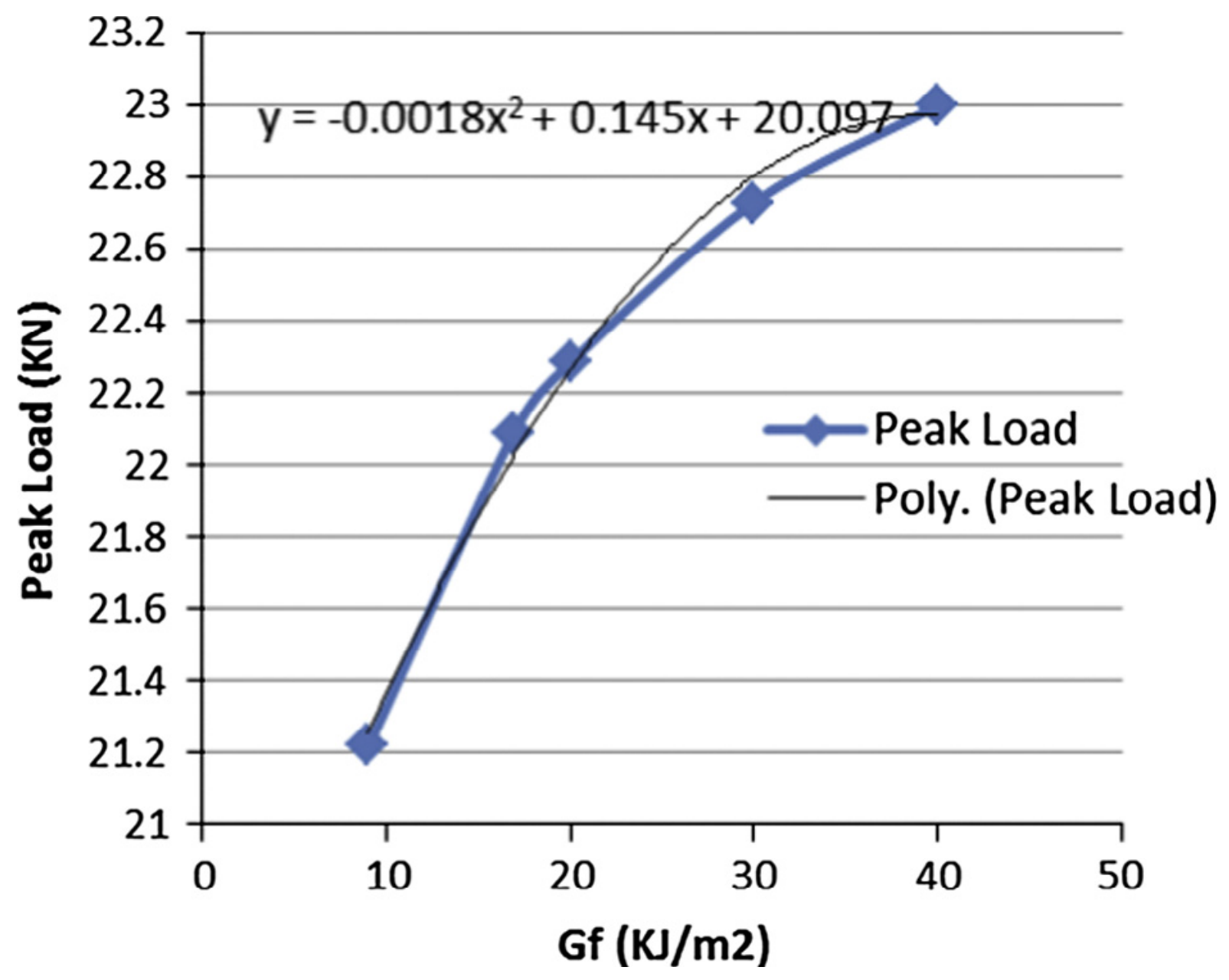

Fig 14: Effect of fracture energy on Peak Load 


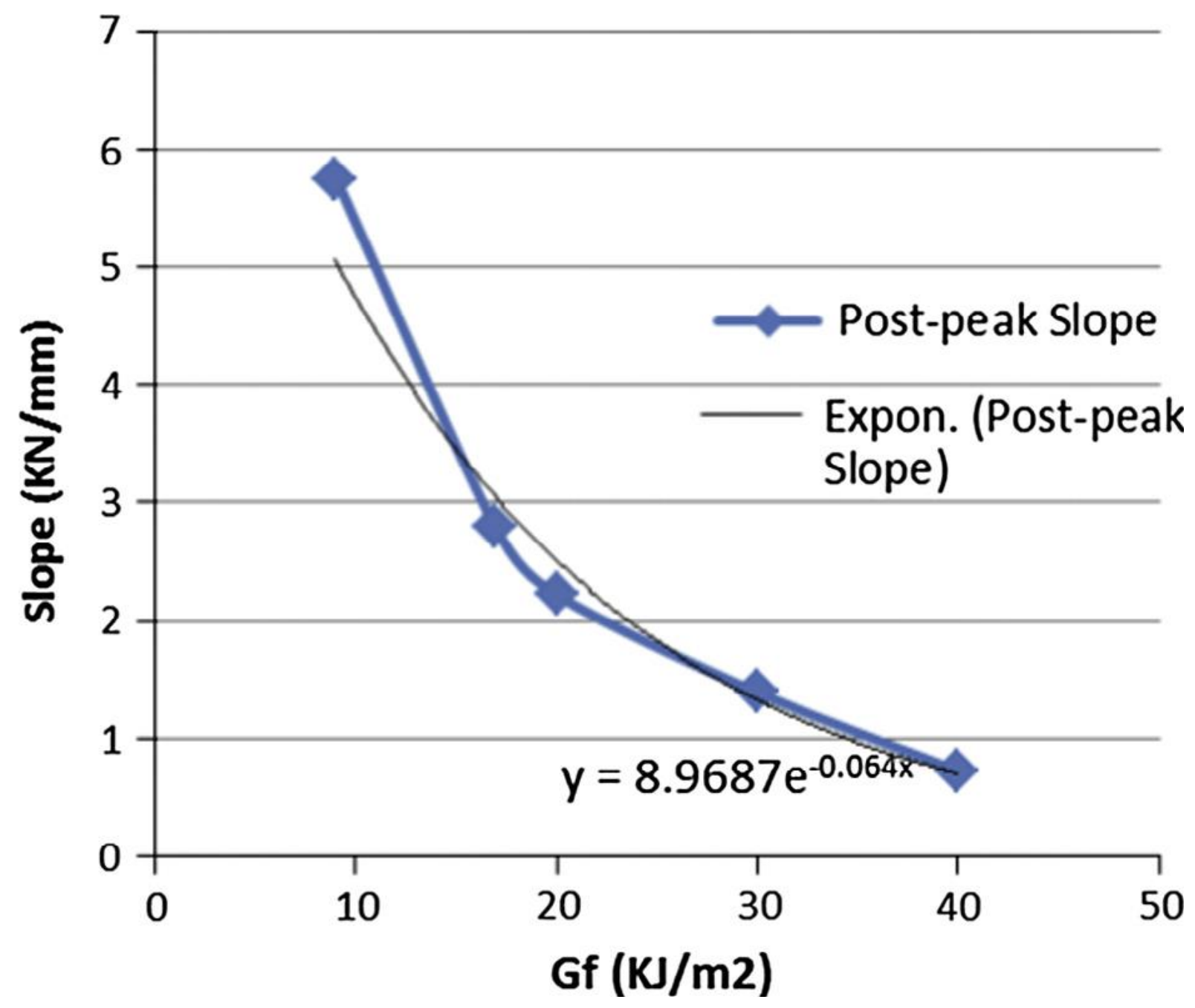

Fig 15: Variation of post-peak slope with fracture energy 


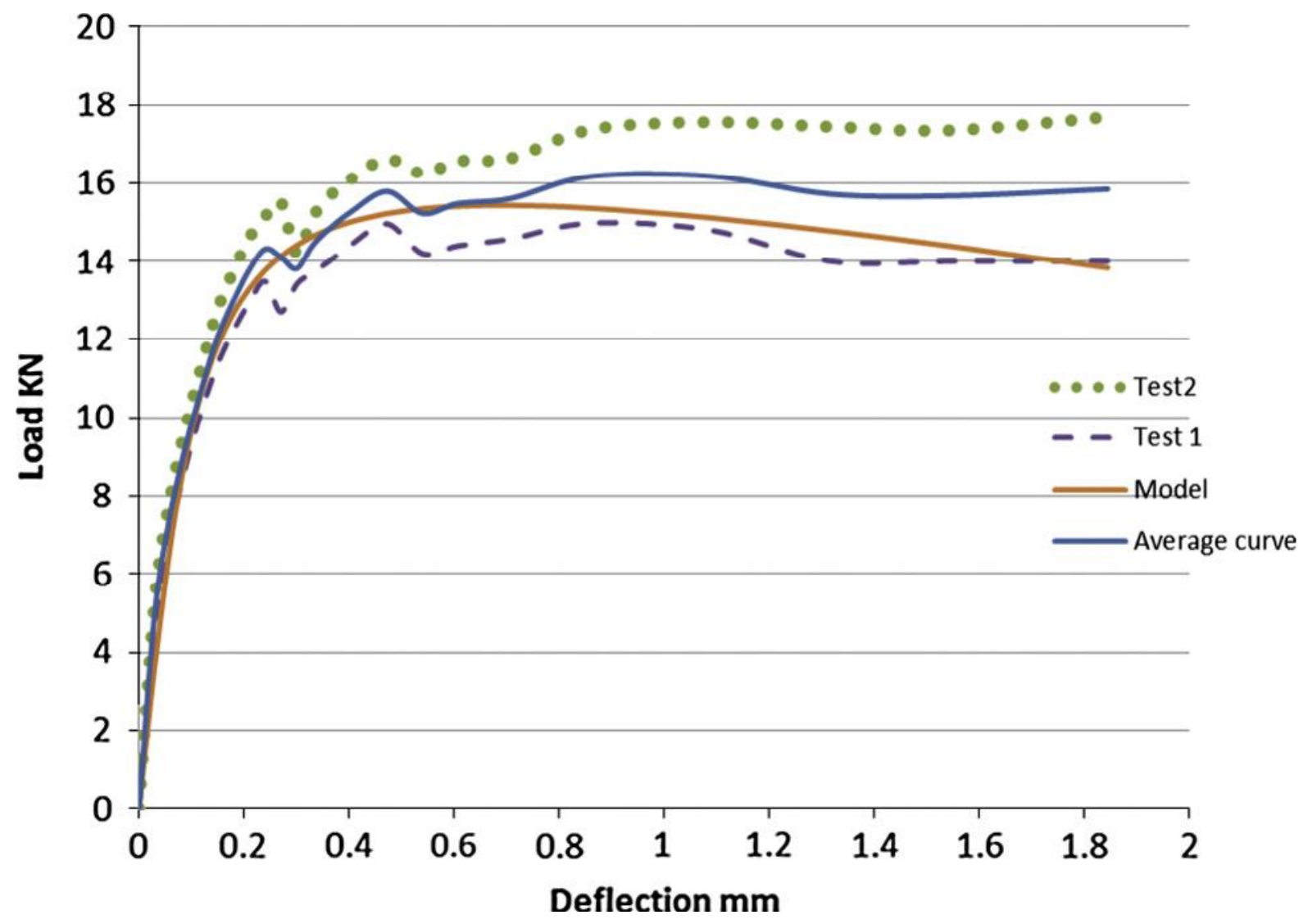

Fig 16: Load-deflection curves for 50x150x550 specimen 


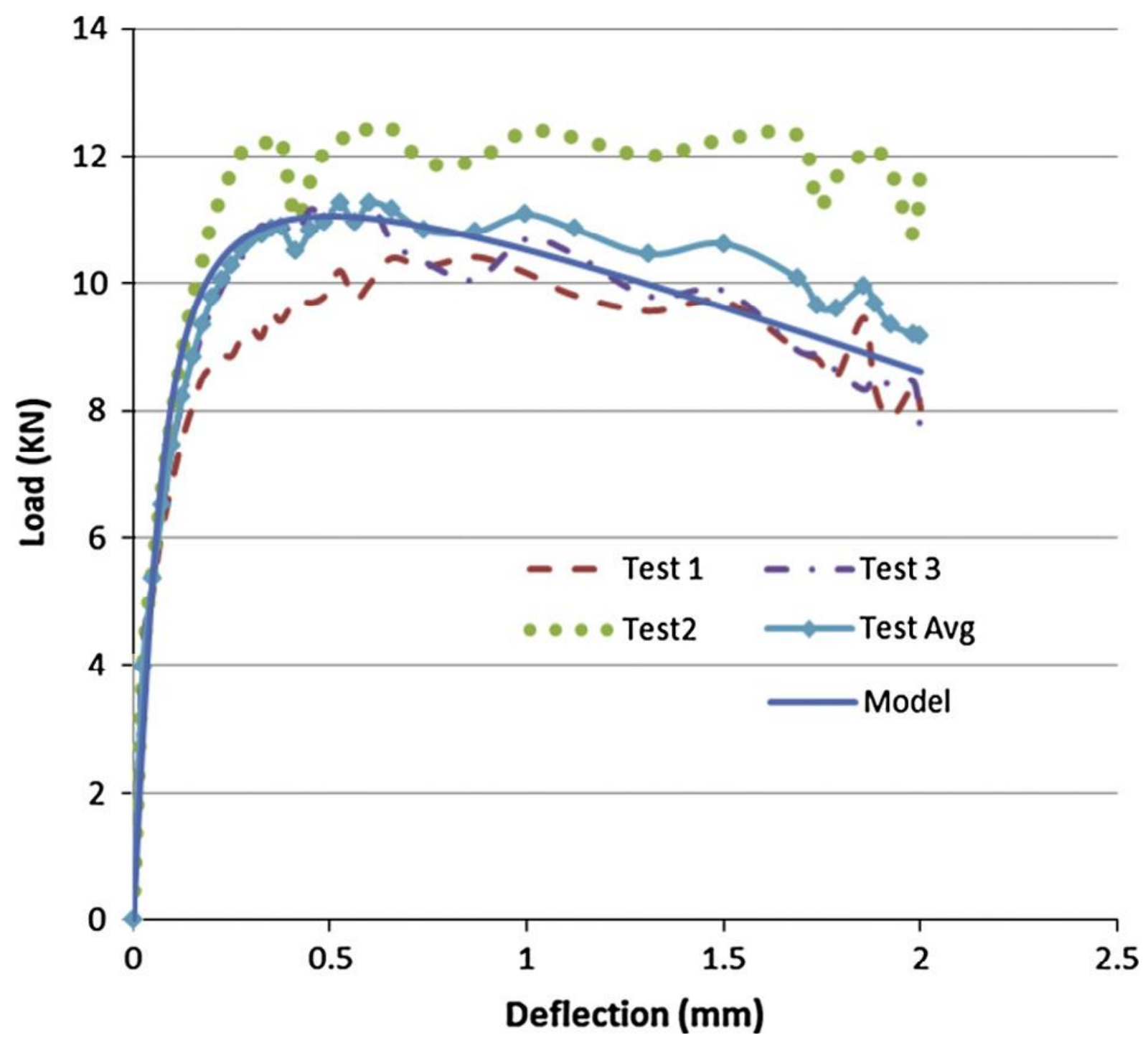

Fig 17: Load-deflection curves for 50×100×350 specimen 


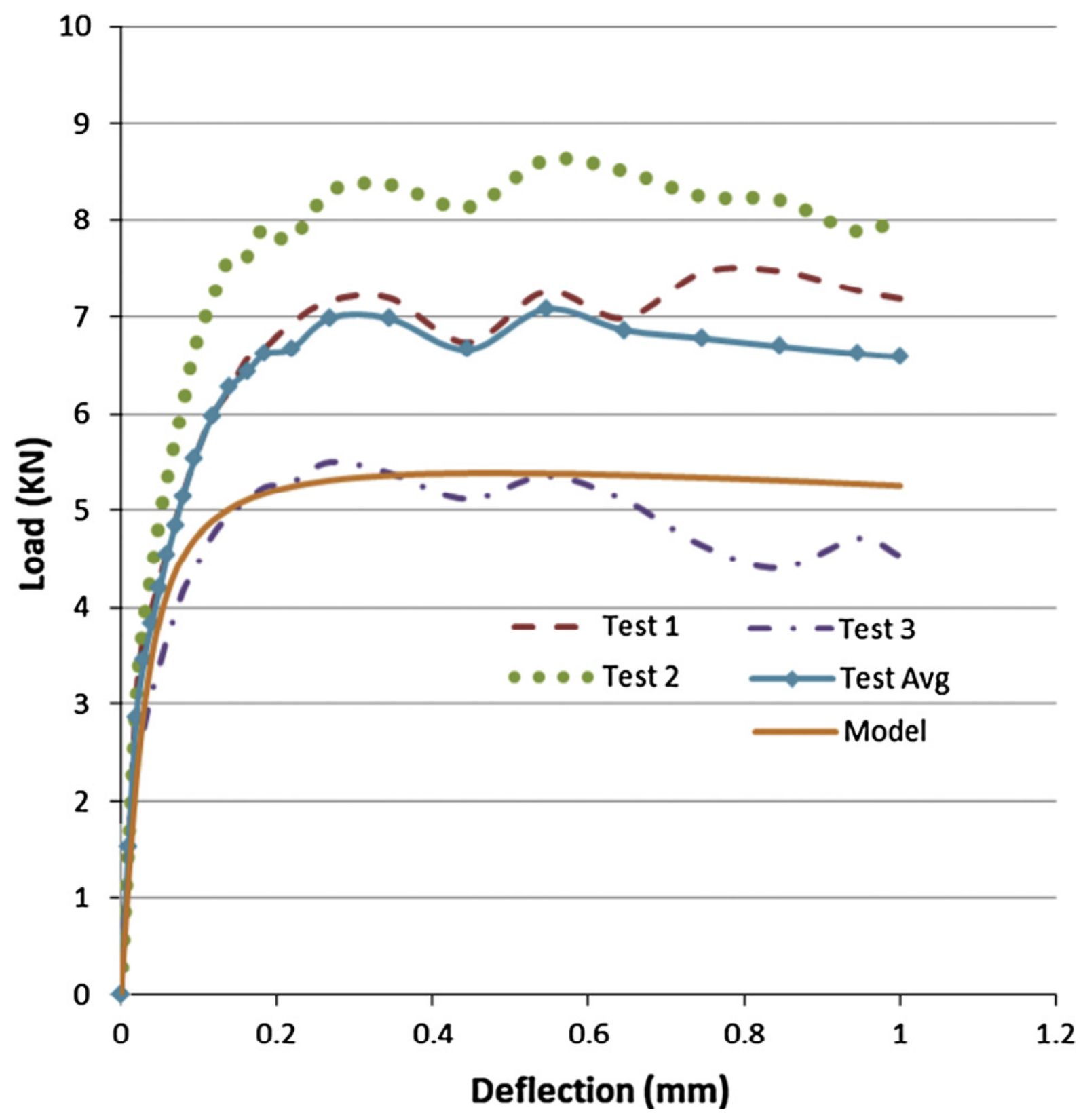

Fig 18: Load-deflection curves for $50 \times 50 \times 200$ 


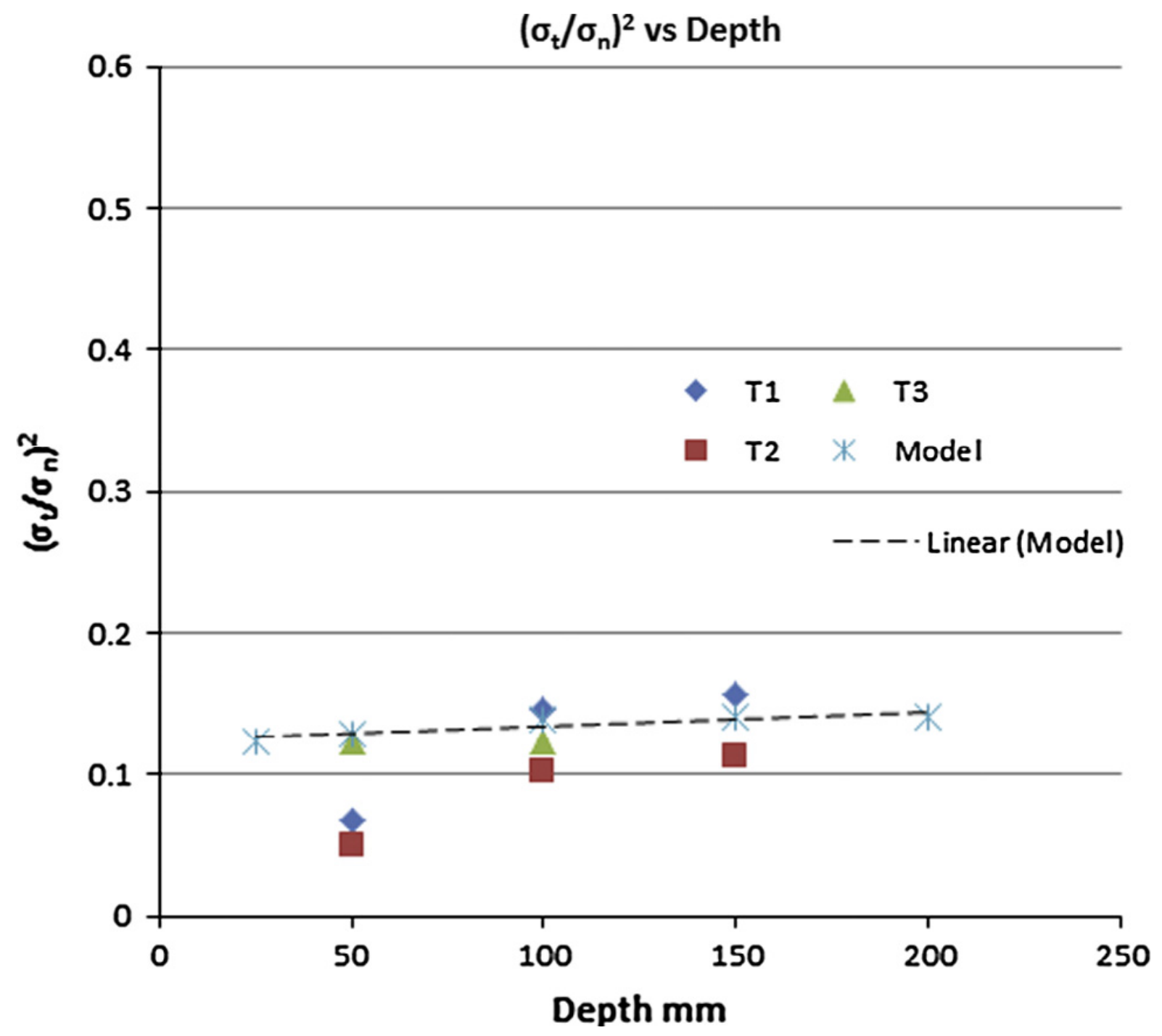

Fig.19: Size effect 
Table 1: UHPFRC mixture proportions

\section{Table 1}

UHPFRC mixture proportions.

\begin{tabular}{ll}
\hline Description & Weight per unit volume $\mathrm{kg} / \mathrm{m}^{3}\left(\mathrm{lb} / \mathrm{yd}^{3}\right)$ \\
\hline 13 mm fibres & $157(265)$ \\
Cement & $657(1107)$ \\
Microsilica & $119(201)$ \\
Slag cement & $418(705)$ \\
Silica sand & $1051(1772)$ \\
High range water reducer & $40(67)$ \\
Water & $185(312)$ \\
\hline
\end{tabular}

Table 2: Modelling parameters

Table 2

Modelling parameters.

\begin{tabular}{lll}
\hline & Parameter & Value \\
\hline \multirow{2}{*}{ Bulk } & Elastic modulus $E$ & $44,654 \mathrm{MPa}$ \\
\multirow{2}{*}{ Cohesive elements } & Poisson's ratio $v$ & 0.2 \\
& Fracture energy $G_{f}$ & $16.9 \mathrm{~kJ} / \mathrm{m}^{2}$ \\
& Tensile strength $\sigma_{t}$ & $8.56 \mathrm{MPa}$ \\
\hline
\end{tabular}


Table 3: Geometry of Three Point Bend (TPB) test specimens

Table 3

Geometry of Three Point Bend (TPB) test specimens.

\begin{tabular}{lll}
\hline Beam size $(\mathrm{mm})$ & Nominal notch size $(\mathrm{mm})$ & Span $(\mathrm{mm})$ \\
\hline 50 wide $\times 150$ high $\times 550$ long & 50 & 450 \\
50 wide $\times 100$ high $\times 350$ long & 33 & 300 \\
50 wide $\times 50$ high $\times 200$ long & 17 & 150 \\
\hline
\end{tabular}

Table 4: Peak Loads

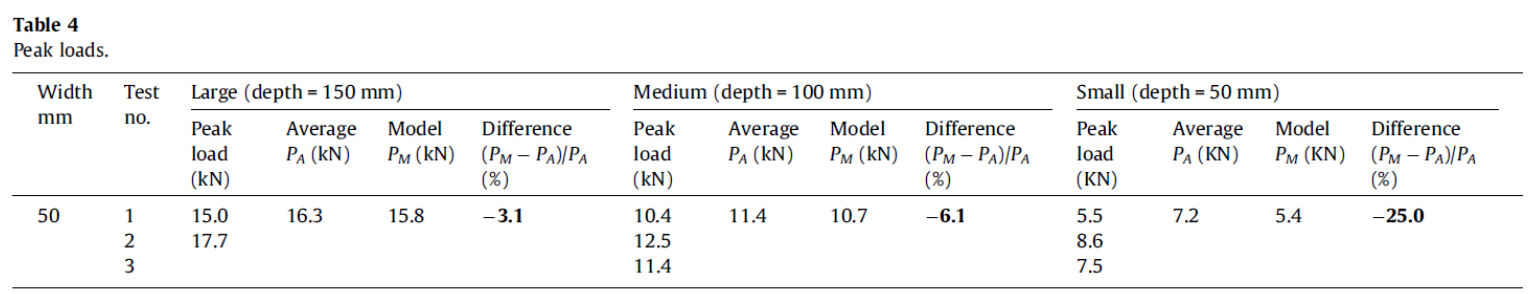

